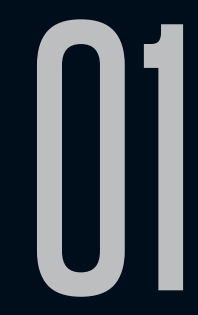

\title{
A BESTA DENTRO DE CADA UM: METAMORFOSES DO VAMPIRO NA LITERATURA BRASILEIRA
}

Pedro Sasse (UFF)

Recebido em 11 mar 2019. Aprovado em 24 mai 2019.
Pedro Sasse é Doutorando em Estudos Literários pela UFF e professor substituto de Teoria Literária e Literatura Brasileira da Faculdade de Formação de Professores da UERJ. É integrante do grupo de pesquisa "Escritos Suspeitos: estudos sobre a ficção criminal contemporânea", coordenado pela prof.a Carla de Figueiredo Portilho. Lattes: http://lattes. cnpq.br/7219234746540444.E-mail: pedro_sasse@ hotmail.com.

Resumo: A publicação da primeira edição de Drácula sucede apenas em alguns anos os famosos assassinatos de Whitechapel, que marcam a ação de um dos primeiros e mais famosos serial killers do mundo, Jack, o estripador. Assim como Jack, o vampiro de Bram Stoker ameaça Londres não apenas fisicamente, mas ontologicamente: ainda que não seja um amaldiçoado morto-vivo, Jack é a confirmação de uma ansiedade crescente que Darwin, entre outros, instaurou na sociedade oitocentista, a de que o homem, longe de ser uma criação especial de Deus, era apenas um animal entre outros. Esse homem cujo interior guarda uma besta sedenta por sangue, representado pela literatura vitoriana de vampiros, encontrará seu espelho realista nos assassinos da literatura de crimes que floresce na mesma época, sem dúvida inflamada por casos como os horrendos crimes de Whitechapel. 
Enquanto o Brasil não se mostra um país pródigo em representações do vampiro propriamente dito, é rico em narrativas que abordam os mesmos medos inspirados por esse predador urbano, chegando, muitas vezes, a incorporar em suas figuras reais traços desses monstros sobrenaturais. Propomos, assim, uma leitura dos predadores urbanos brasileiros à luz dos medos da animalização do homem levantados pela literatura vitoriana, mostrando uma das metamorfoses possíveis do vampiro em território nacional.

Palavras-chave: Cidade; Monstro; Ciência; Medo; Vampiro.

Abstract: The publication of Bram Stoker's Dracula, in 1897, goes just a few years after the Whitechapel murders which have singled out the acts of the most infamous worldwide well-known serial killer, Jack, the Ripper. Similar to Jack, Bram Stoker's vampire threatens London not only physically, but also ontologically: even though Jack is not a cursed undead, he corroborates a growing anxiety which Darwin, amongst others, has introduced in the nineteen-century society, that is, that humans, far from being God's special creation, were merely animals among other animals. This human, who keeps a bloodthirsty beast inside which is represented by the Victorian vampire literature, will be found mirrored by crime literature killers which flourish at the same period, undoubtedly influenced by cases such as the Whitechapel's hideous crimes. Whereas Brazil is not well-known for depicting a more traditional vampire figure, it has nonetheless a myriad of narratives which approach the same fears inspired by this urban predator - one, many times, incorporating typical traces of these supernatural monsters. Hence, we aim at shedding some light upon these Brazilian urban predators based on the fears of animalization brought to life by the Victorian literature, opening the path to one possibility of vampire metamorphosis in our country.

Keywords: City; Monster; Science; Fear; Vampire. 
Drácula, de Bram Stoker, é publicado por primeira vez em 1897. Na mesma época, inúmeros livros e jornais vendiam as histórias escabrosas de Jack, o estripador, como vemos em Chronicles of Crime and Criminals, publicado pela Beaver Publishing em 1895. Perigos de natureza muito distintas, um plenamente ficcional - ainda que vejamos o uso de paratextos que tentem mascarar essa ficcionalidade -, o outro baseado em uma ameaça própria do mundo real. No entanto, como pretendemos demonstrar aqui, Jack e Drácula tem, entre si, mais semelhanças que diferenças, sendo duas manifestações metafisicamente distintas de um mesmo conjunto de ansiedades de seu contexto de produção.

Ainda que tal hipótese nos ajude a enxergar os processos de construção dos monstros na ficção e fora dela, nosso objetivo aqui se inclina para uma investigação não sobre a literatura de medo estrangeira, mas a nacional. A partir de tal paralelo, buscar-se-á demonstrar como a literatura de medo brasileira, influenciada por uma crítica que privilegiava o documental e o realismo às literaturas de cunho mais imaginativo (FRANÇA, 2017, p.27), encontrará nos suspenses psicológicos ${ }^{1}$ uma forma não apenas de lidar com as mesmas ansiedades envolvidas na literatura de vampiros, como utilizará com certa frequência de metáforas, símbolos e alusões a esse monstro na construção de suas narrativas de medo não sobrenatural.

1 Chamamos aqui de suspense psicológico o que a crítica anglófona de ficção de crime denominará Psycho Thriller (SIMPSON, 2010, p.187), subgênero do suspense centrado na representação de crimes como manifestações externas dos processos psicológicos (ou psicopatológicos) de uma mente transtornada. 


\section{MONSTROS CULTURAIS}

Jeffrey Jerome Cohen (2000), em “A cultura dos monstros: sete teses" trabalha com a ideia de que o corpo do monstro é um corpo cultural, ou seja:

O monstro nasce nessas encruzilhadas metafóricas, como a corporificação de um certo momento cultural - de uma época, de um sentimento e de um lugar. O corpo do monstro incorpora - de modo bastante literal - medo, desejo, ansiedade e fantasia (ataráxica ou incendiária), dando-Ihes uma vida e uma estranha independência (p.27)

Cohen afirma, com isso, que a existência dos monstros em uma determinada época está diretamente conectada ao momento cultural da sociedade que os engendra. Medos, fantasias e desejos não só servem de inspiração para o surgimento de tais criaturas, como são elementos impressos em sua própria morfologia, permitindo que, ao fazer o caminho reverso, o crítico seja capaz de desvendar no corpo desses monstros signos sobre a cultura que os formulou.

Através dessa perspectiva, seria possível ler, no corpo do vampiro - a limiaridade ontológica, as presas, o dom proteico medos próprios da sociedade vitoriana. Tal trabalho é empreendido com maestria por Jason Colavito (2008) em Knowing Fear: Science, Knowledge and the Development of the Horror Genre. Colavito restringe um pouco o processo de análise proposto por Cohen, focando-se, sobretudo, nos medos inspirados pelo avanço das ciências e outras formas de produção de conhecimento. O vampiro e, como veremos, também os assassinos seriais -, se enquadrariam, assim, no que Colavito chamará de Biological horror. 
Para Colavito, tanto Drácula, como a criatura de Frankenstein ou Mr. Hyde, monstros eternizados no horror, apontam para um tema central: o conflito entre a natureza humana e a natureza animal, a limiaridade entre o homem e a besta que o habita. Se, hoje, para nós, a visão do homem como um animal pouco apresenta de atemorizante, é preciso lembrar que até o século XIX - sobretudo, até a popularização da visão darwinista do homem - o ser humano apresentava um lugar de destaque na hierarquia da vida no planeta. Remontando a era clássica, a ideia da Grande Cadeia dos Seres (Great Chain of Being), já presente em Platão e Aristóteles, vê o homem como o pináculo de um longo processo evolutivo linear que começa nas criaturas mais simples e, degrau por degrau, incrementa sua complexidade até chegar ao ser humano (COLAVITO, 2008, p.66).

Essa centralidade do homem começa a perder força a partir do iluminismo e continua decaindo ao longo dos Oitocentos, mas é apenas em Darwin que sofrerá o golpe cujos ecos se encontrarão na literatura vitoriana de horror:

Mas importante, e mais devastador, Darwin pela primeira vez divorciou a evolução da velha ideia de progresso, quebrando a Grande Cadeia dos Seres. Na nova evolução, não havia "alto" ou "baixo" ou um progresso inexorável até a divina "perfeição". Em vez disso, havia apenas "mudança". Isso perturbou às mentes do século XIX mais do que qualquer outro aspecto da teoria evolucionária, porque, de golpe, divorciou a humanidade da criação especial de Deus e reduziu, mesmo que apenas por implicação, humanos a apenas outro em muitos animais, sem ao menos ter direito ao 
título de mais alto entre os seres ${ }^{2}$ (COLAVITO, 2008, p.68 - tradução nossa)

Destituídos de qualquer lugar especial na ordem cósmica, o homem é igualado aos demais animais e sua consequente natureza animalesca se torna um aspecto a ser temido. Desse trauma para a sociedade ocidental surgiria, segundo Colavito, o principal elemento necessário para a ascensão do Biological Horror, centrado no medo do lado selvagem da humanidade, na besta escondida dentro de cada um.

Retomando Cohen, esse temor se manifesta morfologicamente no vampiro. Por um lado, o vampiro é tão humano que é capaz de misturar-se aos mortais sem ser notado por aqueles sem a sensibilidade para ver através de sua superfície. Por outro, sua natureza animalesca surge através de suas presas, de sua capacidade de metamorfosear-se em animais e de sua sede por sangue. A mesma dualidade é encontrada em $O$ médico e o monstro, em que Dr. Jekyll representa o humano e Hyde o bestial, e em Frankenstein, em que a criatura, feita a partir de partes humanas, carece dos freios civilizatórios necessários para impedir os assassinatos que comete.

Essa visão, no entanto, impacta também a perspectiva da sociedade sobre o crime. Segundo John Cawelti (1975), em "The New Mithology of Crime", o século XIX apresenta uma mudança na produção da literatura de crime que a afasta do modelo moralpedagógico dos textos do século XVIII:

2 No original: "More importantly, and more devastatingly, Darwin for the first time divorced evolution from the old idea of progress, breaking the Great Chain of Being. In the new evolution there was no "higher" or "lower" or inexorable progress toward divine "perfection." Instead, there was only "change." This disturbed nineteenth century minds more than any other aspect of evolutionary theory, for at a stroke it divorced humanity from God's special creation and it reduced, if only by implication, humans to merely one among many animals, not even worthy of the title of the highest being". 
Um terceiro fator central nas atitudes em relação ao crime no século XIX foi a ascensão de uma abordagem científica e social da análise dos atos criminais, o que levou à investigações empíricas e à suposição de que o crime seria melhor compreendido e tratado não como uma questão moral ou religiosa, mas em termos de seu contexto social e psicológico ${ }^{3}$ (p.330 - tradução nossa)

Do lado positivo, essa mudança colaborou para uma literatura de crime mais crítica em relação à sociedade e às instituições responsáveis pela manutenção da ordem. Por outro, divorciando o crime de suas influências religiosas, tornou o homem o único culpado possível para os mais horrendos atos. Unindo-se a essa visão, a popularização dos assassinos seriais através de Jack, o estripador, em Londres, e H. H. Holmes, nos EUA, vemos esse novo criminoso como a hipérbole da animalização do homem:

Os assassinos no fin de siècle pareciam servir perfeitamente para confirmar a teoria de Darwin de que os homens eram meros animais, presos unicamente ao natural instinto de morrer ou ser mortos $^{4}$ (COLAVITO, 2008, p.77 - tradução nossa)

Uma segunda tese levantada por Cohen é a de que "O monstro sempre escapa". Tal tese tem a difícil tarefa de dar conta de um sério problema para a própria proposta criada pelo autor: se o monstro é um corpo cultural em que se inscrevem as ansiedades

3 No original: "A third major factor in nineteenth century attitudes toward crime was the rise of a scientific and social approach to the analysis of criminal deeds, which led to empirical investigations of the causes of crime and to the assumption that crime could be best understood and dealt with not as a moral or religious matter but in terms of its social or physiological background".

4 No original: "The murders in the fin d. Hick seemed tailor-made to confirm Darwin's theory that humans were merely animals, beholden only to the natural instinct to kill or be killed". 
de um determinado momento cultural, a mudança de momento cultural deveria ter como consequência a mudança também nos monstros concebidos pelas gerações seguintes. No entanto, o que vemos de forma clara na história do horror é uma recorrência de certos monstros arquetípicos, dentre os quais o vampiro assume posição central:

Ao falar do novo tipo de vampiro inventado por Bram Stoker, podemos explorar a sexualidade transgressiva mas irresistível do estrangeiro conde como sutilmente atraente para Jonathan Harker da mesma forma que Henry Irving, o mentor de Stoker, o era para Stoker. Ou podemos analisar a apropriação autodepreciativa que Murnau faz do mesmo demônio em Nosferatu, no qual, diante do nascente fascismo, os elementos subterrâneos do desejo sobem à superfície por meio da praga e da degradação corporal. Anne Rice deu ao mito uma reescrita moderna, na qual a homossexualidade e o vampirismo foram reunidos de forma apoteótica; 0 fato de que ela criou, nesse processo, um fenômeno de cultura pop não é algo sem importância, especialmente em uma época na qual o gênero, visto como um constructo, tem sido questionado em quase todo registro social. No recente sucesso de bilheteria do filme Bram Stoker's Dracula, de Francis Coppola, o subtexto homossexual presente desde a aparição da lésbica Laura, de Sheridan Le Fanu (Carmilla, 1872), tal como os corpúsculos vermelhos que servem como o leitmotif do filme, sobe à superfície, primariamente como consciência da AIDS, transformando a doença do vampirismo em uma forma sádica (e muito medieval) de redenção por meio dos tormentos do corpo que sofre. Nenhuma coincidência, pois, que Coppola estivesse produzindo um documentário sobre 
a AIDS ao mesmo tempo em que ele estava trabalhando no Drácula (COHEN, 2000, p.28-29)

Podemos dividir, a partir dessa perspectiva, a constituição do monstro em dois eixos: de um lado, temos o monstro enquanto forma, referencial imagético mais ou menos cristalizado na mente dos leitores, carregando não apenas a corporificação das ansiedades de sua época, mas também as cicatrizes de sua apropriação ao longo do tempo, a história de sua própria recepção e ressignificação. Do outro, temos o monstro enquanto conteúdo, a constelação de temas, fantasias, medos e desejos inspirados por esse monstro. Esse conteúdo, por um lado, pode se manifestar em diversos corpos monstruosos de uma determinada época - sendo o que permite que Colavito costure Drácula, Hyde, Frankenstein e Jack, o estripador, no horror biológico -, e, por outro, pode encontrar novos corpos monstruosos em diferentes épocas ou lugares que compartilham de ansiedades semelhantes.

Esse vampiro enquanto forma, imagem, que antecede inclusive suas manifestações vitorianas, remontando ao folclore medieval na Europa, é apropriado enquanto símbolo já consolidado no gênero do horror e ressignificado para se adequar a diversos conteúdos, do homoerotismo de Carmilla aos conflitos juvenis da saga Twilight. Pensando, no entanto, no conteúdo cultural lido nesse vampiro vitoriano, vemos que os mesmos medos podem manifestar-se em outras figuras monstruosas, não necessariamente sobrenaturais. Enquanto as apropriações mais recentes do vampiro, como o hollywoodiano Dracula untold (2014), de Gary Shore, ressignificam de tal forma o conteúdo do monstro que o afastam inclusive do gênero de horror, vemos em obras como $O$ silêncio dos inocentes, de Thomas 
Harris, uma obra de medo não sobrenatural que tem muito mais a dizer sobre os medos inspirados pelo vampiro vitoriano que diversas leituras contemporâneas do vampiro de fato. Dr. Hannibal Lecter revive cada aspecto do Drácula de Stoker: desde o comportamento aristocrático à sede de sangue, da natureza animalizada à capacidade hipnótica, apontando para os horrores dessa besta sedenta por sangue que residiria no interior de cada homem.

Retomamos, assim, a hipótese de que o vampiro vitoriano encontra no conteúdo cultural de sua monstruosidade os mesmos elementos explorados pelas narrativas de Jack, o estripador, e, posteriormente, H. H. Holmes. Podemos destacar, na análise de Colavito sobre Drácula - amparada por uma leitura de seus predecedores oitocentistas, The Vampyre, de Polidori, Varney, the Vampire, de Rhymer e o já citado Carmilla - alguns temores compartilhados entre a literatura centrada em vampiros e psicopatas: o já comentado medo da besta interior, da natureza do homem e sua capacidade de subjugar seu lado racional e moral; o medo de tornar-se a vítima desse animal-homem - temor, alimentado pelo aumento da criminalidade e da exposição midiática dessa criminalidade nos grandes centros urbanos; e, por último, um medo de cunho sexual, indissociável da nova percepção da natureza selvagem do homem, mas também alimentado pelas ansiedades vitorianas sobre as mudanças na forma como o sexo era encarado na sociedade, sobretudo em relação às mulheres.

Já vemos no pioneiro vampiro de Polidori a presença da dualidade animalesca representada pelo vampiro. Em Polidori, no entanto, esse medo se concentra, sobretudo, no homem enquanto vítima desse predador capaz de se misturar entre os demais mortais. Essa 
animalização do homem que se consolida na literatura vitoriana encontra seu germe no século anterior tendo Sade como portavoz. Nas obras do autor francês, vemos, através do discurso dos burgueses e aristocratas, vemos como a aceitação da natureza animal do homem serve como libertação da moral cristã e justifica a consumação dos mais cruéis atos. Em Justine, por exemplo, veremos o marquês de Bressac legitimar o assassinato da mulher que o criou levando a ideia da perda do lugar privilegiado do homem na natureza que começava, então, a se formar nas ciências ocidentais:

- O que importa para a natureza sempre criadora aquela massa de carne que hoje tem a forma de uma mulher se reproduza amanhã sob a forma de mil insetos diferentes? Ousarás dizer que a construção de um indivíduo como nós custa mais à natureza que a de um verme e que, por conseguinte, ela deva dar-Ihe mais atenção? Ora, se o grau de atenção ou melhor, de indiferença, é o mesmo, que pode ela fazer, senão pelo que chamamos de crime de um homem, que um outro seja transformado em mosca ou em escarola? Quando me tiverem provado a sublimidade de nossa espécie, quando me tiverem demonstrado que ela é tão importante para a natureza que necessariamente suas leis se irritam com sua destruição, então eu poderei crer que essa destruição é um crime; mas quando o estudo mais ponderado da natureza me tiver provado que tudo o que vegeta sobre o globo, a mais imperfeita das suas obras, tem um preço igual aos seus olhos, jamais suporei que a mudança de um de seus seres em mil outros possa ofender suas leis; eu me direi: todos os homens, todas as plantas, todos os animais que crescem, vegetam, se destroem pelos mesmos meios, não recebendo jamais uma morte real, mas uma simples variação 
no que as modifica, tudo, digo, tudo se perseguindo, destruindo-se, procriando indiferentemente, aparece um instante sob uma forma e no instante seguinte sob uma outra, podem ao capricho do ser que quer ou que pode move-los, mudar milhares e milhares de vezes num dia sem que uma única lei da natureza possa ser afetada por instantes sequer (SADE, 1979, p.39)

Em uma literatura constringida pela moral vitoriana, no entanto, os monstros libertos de Sade não encontrariam espaço. É preciso, então, que essa animalização, mais que uma total entrega aos instintos - ainda que racionalizados em Sade - seja tensionada com o lado consciente, racional e, sobretudo, moral. Varney, no romance de Rhymer, já expressa a angústia de sua condição, adicionando à ameaça externa representada por essa natureza animal do homem outra interna, a de que nós mesmos sejamos tomados por tal condição, nos tornemos o monstro:

É seu sofrimento mental e sua inabilidade para alinhar sua moralidade com sua fome animal fundamental que o define, e o destrói. Ele é a besta, suspensa entre o mundo animal e o mundo humano $^{5}$ (COLAVITO, 2008, p.85 - tradução nossa)

Em Drácula, ainda que o dilema moral não apareça tão latente, vemos as amarras morais cerceando o monstro através da eficácia da religião contra a criatura. Dessa forma, a animalização do homem pode e é controlada através de uma instância superior, apontando para um resguardo para o homem diante da violência predatória da natureza.

5 No original: "It is his mental anguish and his inability to rectify his morality with his base, animal hungers that define him, and destroy him. He is a beast, suspended between the animal world and the human". 
Colavito ressalta como a mais explícita metáfora da condição animalizada do homem no vampiro é a presença dos caninos que surge em Varney. Símbolo do animal predatório, oposto à civilidade humana, o canino é o instrumento que servirá para saciar o desejo incontrolável do homem pelo sangue, pela vida de suas presas. Contudo, junto a essa analogia, Colavito mostra como, em muitas leituras, outro desejo predatório humano é também simbolizado pelos caninos: o sexual. Em Drácula, abundam interpretações psicanalíticas da relação entre o ataque do vampiro e o ato sexual:

Provavelmente, em toda a literatura de horror, nenhum outro livro reuniu tal volume de interpretações psicossexuais. (...) A maior parte dos críticos (...) concorda que as presas do vampiro representam o pênis, que sua mordida é uma agressão oral do sexo genital normal e que o romance lida primariamente com as ansiedades vitorianas sobre mudanças de papeis sexuais e a repressão dos desejos sexuais ${ }^{6}$ (2008, p.88 tradução nossa)

Enquanto Varney e Drácula representam o ataque predatório sexual masculino, Carmilla, assim como as asseclas de Drácula, corporifica as ansiedades sobre a progressiva emancipação da mulher e o domínio de sua própria sexualidade, unindo a isso, claro, o homoerotismo na obra de LeFannu. A femme fatalle, arquétipo recorrente na literatura finissecular, encontrará na figura do vampiro uma de suas mais recorrentes manifestações ao longo do tempo.

6 No original: "Probably in all horror literature, no other book has garnered such a volume of psychosexual interpretation. (...) Most critics (...) agreed that the vampire's fangs represent the penis, that his bite is an oral aggression of normal genital sex, and that the novel deals primarily with the Victorian anxiety about changing sex roles and the repression of sexual desire". 
Se olharmos, agora, para as narrativas de psicopatas que começam a se desenvolver nessa época, perceberemos que o conteúdo aterrorizante encontrado nessas histórias encontrará fortes paralelos com aqueles próprios da literatura vitoriana de vampiros. Clive Bloom (2017), em "Dracula and the Psychic World of the East End of London", defende mais do que um conteúdo semelhante, apontando que haveria conexões diretas entre o vampiro construído por Stoker e a figura de Jack, o estripador.

Bloom parte, para sua pesquisa, de uma dúvida central: por que, havendo tão claras semelhanças entre a história de Drácula os crimes de Jack, não há nenhuma menção explícita ao assassino no romance de Stoker?

Para defender a ideia de que, de fato, havia tal semelhança, Bloom mostra como, não só a mídia da época construía uma imagem de Jack que se assemelhava ao monstro arquitetado por Stoker, como também, em um dos primeiros romances sobre o assassino, The True History of Jack The Ripper [1905], de Guy Logan, há claras referências ao vampiro. A narrativa de Logan é centrada na figura do Dr. Mortemer Slade e sua escapada de um manicômio em 1887. Slade sofria de uma peculiar insanidade moral, que não afetava em nada sua razão - apontando já para o perfil dos psicopatas que se consolidarão na literatura décadas mais tarde com $O$ assassino em mim, de Jim Thompson, e O talentoso Ripley, de Patrícia Highsmith -, permitindo-o camuflar-se entre os demais sem dificuldades, sendo entregue apenas por seu sorriso, descrito pelo autor como "not a nice smile. His lips were thin, his teeth rather sharp and discoloured" (Logan, Apud BLOOM, 2017, p.120). Bloom parte dessa clara referência para mostrar outras semelhanças entre os personagens: 
Slade acredita que "todo homem é louco, mas alguns são mais loucos que outros". Assim como Drácula, ele também circula disfarçado "[assumindo] com o propósito de disfarce uma barba falsa e um bigode". Sua senhoria acredita que ele é um "nobre refugiado da Roosia [sic]" e, como $\mathrm{O}$ estripador, ele escreve suas letras com "sangue humano líquido", mas para fazer a conexão mais clara, somos informados que "seus lábios eram finos, seus dentes afiados e descoloridos". Suas caças estão em Whitechapel, ele tem olhos hipnóticos e ele se delicia no "êxtase de matar", sinalizando-se como Jack o estripador. Como detalhe, adiciona-se o fato de que Slade tem uma "alma como as de ghoul", confirmando suas credenciais góticas ${ }^{7}$ (p.120 - tradução nossa)

O objeto central de análise de Bloom, no entanto, é uma versão islandesa de Drácula editada por Valdimar Ásmundsson que, retraduzida ao inglês há poucos anos, revelou uma narrativa bem distinta de sua versão original. Sem poder precisar se a versão de Valdimar foi de fato autorizada pelo próprio Stoker ou se é fruto de uma alteração radical feita pelo próprio jornalista islandês, Bloom vê a obra como um possível indício de que, se o Drácula original não parece associar-se diretamente ao caso de Jack, tal associação era existente no imaginário popular - tanto que foi realizada na versão de Ásmundsson.

Já no prefácio de Powers of Darkness [Makt Myrkranna], nome que recebeu a versão islandesa, podemos notar a clara aproximação 7 No original: "Slade believes "all men are mad, but that some are more mad than others". Like Dracula he too goes around in disguise "[assuming] for the purpose of concealment a false beard and moustache". His landlady believes him to be a "refugee nobleman from Roosia [sic]" and like the Ripper he writes his letters in "liquid human blood", but to make the connection clearer, we are told that "his lips were thin, his teeth rather sharp and discoloured". His prey is in Whitechapel, he has hypnotic eyes and he revels in "the ecstasy of killing" signing himself Jack the Ripper. To add to the detail Slade has a "ghoul like soul" confirming his gothic credentials". 
com Jack o estripador. Nesse prefácio, o autor teria recorrido a uma estratégia semelhante àquela usada por Walpole em $O$ castelo de Otranto, apresentando a obra como uma narrativa ancorada na realidade. Para tal, utilizaria como ponto de contato justamente os crimes de Whitechapel:

Eu enfatizo novamente que a misteriosa tragédia descrita aqui é completamente verdadeira em todos os seus aspectos externos... essa série de crimes, que parecem incompreensíveis mas parecem derivar da mesma raiz - e criaram em seu tempo tanto horror no público quanto os infames assassinatos de Jack o estripador [alternativamente na nova tradução: Jacob the Disemboweller], que ocorreram pouco tempo depois ${ }^{8}$ (Bram Stoker/ Valdimar Ásmundsson, Apud BLOOM, 2017, p.122-123 - tradução nossa)

A narrativa em si também é drasticamente alterada, havendo mudança não só de nomes de personagens, como localidades da obra, redução drástica dos diálogos e dissolução da forma epistolar em prol de um narrador onisciente. Se, por um lado, tais alterações, como o nome dos personagens, visam a adaptar a obra à realidade de leitores da Islândia, outras alterações poderiam indicar uma aproximação entre Drácula e as narrativas mais populares, como os penny dreadful que circulavam na Inglaterra desde meados do século XIX.

Em alguns diálogos da obra, podemos ver novos rastros da conexão entre os dois personagens. Ainda na primeira parte, em que Harker se encontra no castelo do conde, o vampiro se interessa

8 No original: "I emphasize again that the mysterious tragedy described here is completely true in all its external aspects... this series of crimes, which see incomprehensible but appear to stem from the same root - and have created in their time as much horror within the public as the infamous murders by Jack the Ripper [alternatively in the new translation: Jacob the Disemboweller], which occurred a short time later". 
por Londres, ficando profundamente entusiasmado ao ouvir a menção aos assassinatos de Whitechapel:

"Sim," o conde disse, sem fôlego e com entusiasmo... "Sim, esses crimes, esses horríveis assassinatos; aquelas mulheres massacradas encontradas em sacos, boiando no Tâmisa; o sangue que corre - corre e flui - sem que nenhum assassino seja encontrado." ... ele parecia estar lambendo os lábios com desejo... "Sim, é uma tragédia," ele disse, "e esses assassinados nunca serão desvendados - jamais. Seu escritor, Conan Doyle, escreveu diversos bons livros sobre Londres... De acordo com eles, apenas dois ou três por cento de todos os casos de homicídio são resolvidos. Sim, Londres é de fato uma cidade notável ${ }^{9}$ (BRAM STOKER/ VALDIMAR ÁSMUNDSSON, Apud BLOOM, 2017, p.126 - tradução nossa)

A estratégia de Ásmundsson de aproveitar-se do clima de medo transmitido na realidade pela figura de Jack para alimentar os horrores da ficção de que traduzia e adaptava nos confirma a proximidade existente entre os medos projetados pelos psicopatas e vampiros nessa virada para o século $X X$.

Dessa forma, vemos que não há uma questão simples de fonte e influência envolvida na questão entre a literatura de vampiro e a literatura de crime vitoriana, mas um diálogo em que as obras de psicopatas beberão do legado deixado por Drácula e outras histórias desse horror biológico - sobretudo no conflito da besta interior 9 No original: '“Yes,' the Count said, breathless with excitement...'Yes, these crimes, these horrible murders; those slaughtered women found in sacks, drifting in the Thames; this blood that runs - runs and flows - with no killer to be found.'...he seemed to be licking his lips with lust...'Yes, it is a tragedy' he said, 'and these murders will never be solved - ever. Your writer, Conan Doyle, has written many good books about London... According to them, barely two or three percent of all homicide cases are solved. Yes, London is indeed a remarkable city."' 
enquanto essas histórias sobrenaturais utilizarão os medos urbanos como forma de intensificar seus próprios efeitos estéticos.

Frutos de um mesmo momento sociocultural, os primeiros psicopatas da literatura e os monstros sobrenaturais vitorianos, sobretudo o vampiro, podem mudar seus símbolos, mas apontam para um mesmo fundo comum de medos próprios de sua realidade, alguns dos quais se perpetuarão até a contemporaneidade.

Tendo sido possível demonstrar, através dessa leitura do horror biológico de Colavito e da monstruosidade cultural de Cohen, que podemos estreitar as relações entre o monstro sobrenatural e o monstro humano - e para ser mais específico, entre o vampiro nos moldes vitorianos e esse assassino psicopata que surge no mesmo momento -, propõe-se, então, que esse monstro humano, por encontrar mais espaço e aceitação na crítica e na recepção da literatura brasileira, servirá não apenas para corporificar as ansiedades relacionadas ao lado animalizado do homem, como, ainda, para dialogar diretamente com a tradução da literatura de vampiros, ao utilizar metáforas, símbolos e outras alusões a esse personagem já consolidado no imaginário popular.

\section{METAMORFOSES DO VAMPIRO NO BRASIL}

Ainda que recentemente grupos de pesquisa especializados na literatura do medo e do fantástico venham descobrindo cada vez mais uma tradição perdida do insólito na literatura brasileira, ainda é possível afirmar que carecemos de uma forte produção de horror sobrenatural no país. Dessa forma, vampiros encontraram escasso terreno para se desenvolver, ficando restritos a alguns contos regionalistas e à literatura mais recente. No entanto, se retomarmos, agora, essa 
paridade entre o conteúdo da monstruosidade do vampiro e do psicopata, encontraremos em nossa literatura uma pródiga produção de obras centradas nos mesmos elementos culturais explorados por Drácula: o medo do lado animal do homem, o perigo de ser caçado nas ruas escuras da cidade e a ameaça sexual envolvida nesses ataques.

Nosso primeiro exemplo surge poucos anos após a publicação da obra de Stoker. Em 1906, João do Rio publica "Dentro da noite" na Gazeta de Notícias, conto que mais tarde servirá para nomear a coletânea de contos estranhos, obscuros e perturbadores do escritor. Nossa escolha é justificada pela clara alusão ao vampirismo que tematiza o conto: o protagonista - e monstro - da história descobre-se acometido por um desejo incontrolável de furar os braços de sua noiva, impulso que será levado a cabo e terminará transformando-o paulatinamente em um predador noturno. Se, como notou Bloom, é curioso que Drácula não apresente nenhum ponto de contato direto com os casos de Whitechapel, que possivelmente serviram para impulsionar os efeitos da obra, em "Dentro da noite" vale ainda ressaltar como o oposto ocorre. Apesar da clara referência ao vampirismo, nenhuma menção a Drácula ou qualquer outra obra vitoriana é encontrada - ainda que, como tradutor de Oscar Wilde, João do Rio tivesse claro contato com tal literatura. Veremos, no entanto, menção direta justamente ao par não sobrenatural do vampiro, comparando o protagonista ao temido estripador inglês e, assim, reforçando a ideia de que, tal figura encontraria paralelos com o conde criado por Stoker.

O conto narra o encontro entre Rodolfo e Justino em um vagão do trem nas noites cariocas. Rodolfo, o protagonista, já se encontra plenamente rendido ao seu lado bestial, transformado em um 
predador noturno, e encontrava-se ali justamente em busca de sua próxima vítima, "pálido, suando apesar da temperatura fria, e com um olhar tão estranho, tão esquisito" (RIO, 2002. p.17), como nota seu amigo. O conto, então, passa para uma narrativa em moldura, na qual Rodolfo contará como chegou àquela condição. Justino, mais que puro espectador, funcionará como contraponto à perspectiva de Rodolfo, justificando os atos de seu companheiro conforme o vê culpar-se pela situação em que se encontra.

Rodolfo confessa-se acometido por uma espécie de vício ou tara do qual não consegue livrar-se e não pode resistir. A nevrose, em termos de Rodolfo, eclode durante um baile ao qual havia ido com sua noiva, a submissa Clotilde. Vendo seus braços descobertos pela primeira vez, sente, subitamente, um desejo crescer dentro de si:

a vontade de tê-los só para os meus olhos, de beija-los, de acaricia-los, mas principalmente de fazê-los sofrer. Fui ao encontro da pobre rapariga fazendo um enorme esforço, porque o meu desejo era agarrar-Ihe os braços, sacudi-los, aperta-los com toda a força, fazer-lhes manchas negras, bem negras, feri-los... Porque? Não sei, nem eu mesmo sei - uma nevrose! (RIO, 2002, p.19)

Longe de entregar-se abertamente ao desejo, Rodolfo lutará contra o impulso monstruoso que toma sua vontade. Nesse conflito entre o Rodolfo civilizado e o instinto bestial que cresce em seu corpo, vemos de forma clara o medo desse lado animal do homem, talvez de forma mais impactante do que aquela encontra nos monstros sobrenaturais: mesmo sem nenhuma mudança ontológica, o ser humano estaria suscetivel a se transformar em um monstro sem que nada pudesse fazer para lutar contra tal condição ou preveni-la. 
Conforme o tempo passa, a nevrose que de início era um impulso bruto, depura-se em um desejo sádico refinado:

Contive-me dias, meses, um longo tempo, com pavor do que poderia acontecer. O desejo, porém ficou, cresceu, brotou, enraigou-se na minha pobre alma. No primeiro instante, a minha vontade era bater-lhe com pesos, brutalmente. Agora a grande vontade era de espetá-los, de enterrar-Ihes longos alfinetes, de cozê-los devagarinho, a picadas (RIO, 2002, p.19)

Nessa sutil tortura encontraremos a grande proximidade com o vampiro. O ato inaugural, cometido pouco depois contra Clotilde não só cria uma alusão ao ato sexual semelhante à da mordida do vampiro como o próprio Rodolfo indica a possibilidade de beber o sangue, confirmando o paralelo com o monstro sobrenatural: "É preciso pagar ao meu ciúme a sua dívida de sangue. Deixe espetar o alfinete." "Está louco, Rodolfo?" "Que tem?" "Vai fazer-me doer." "Não dói." "E o sangue?" "Beberei essa gota de sangue como a ambrosia do esquecimento." (p.20)

É no contraponto de Justino que vemos a menção a dois nomes próprios do lado não sobrenatural das ansiedades sobre o lado bestial do homem, Sade e Jack o estripador. O amigo de Rodolfo, como os vilões de Sade, usa as próprias ferramentas da razão para justificar o ato hediondo:

- Caso muito interessante, Rodolfo. Não há dúvida que é uma degeneração sexual, mas o altruísmo de S. Francisco de Assis também é degeneração e o amor de Santa Teresa não foi outra coisa. Sabes que Rousseau tinha pouco mais ou menos esse mal? És mais um tipo a enriquecer a série enorme dos discípulos do marques de Sade. Um homem 
de espírito já definiu o sadismo: a depravação intelectual do assassinato. És um Jack-the-rippercivilizado, contentas-te com enterrar alfinetes nos braços. Não te assustes (p.21)

Rodolfo, após o fim de seu noivado com Clotilde devido à descoberta das torturas por parte de uma empregada da família, passará, como Jack, a buscar suas presas entre as prostitutas da cidade. No entanto, numa fase intermediária de sua nevrose, não as ataca, mas tenta pagar para ter seu desejo saciado, proposta que rapidamente será descartada por aquelas mulheres, que sentiam repulsa pelo vício de Rodolfo.

Assim, o personagem acaba entregando-se plenamente à sua condição e passa a buscar as vítimas nas estações e vagões de trem, alcançando assim, o ponto em que se encontrava no momento de sua narração. A conversa é interrompida com a passagem de uma jovem loira, que atiça o desejo de Rodolfo. Ele despede-se de seu amigo, descendo na mesma estação de sua possível presa. O conto se encerra entre a expectativa dos gritos da vítima e a partida do trem pela noite, deixando em aberto o destino do monstro e sua vítima na noite carioca.

Ainda que João do Rio tenha outras obras que dialogam com os medos vitorianos destacados anteriormente - como o sádico Barão Belfort, que vampiriza a emoção de suas vítimas por uma incapacidade de sentir qualquer coisa por conta própria, ou a enigmática femme fatalle de "O carro da semana santa", explorando a temática do sexo e da heresia -, vale destacar que tal diálogo se manifesta em outros autores e períodos da literatura brasileira. Dentre eles, gostaríamos de destacar Lúcio Cardoso. 
Herdeiro do gótico urbano de João do Rio, o autor mineiro, mais conhecido por sua produção regionalista, têm, na trilogia do Mundo sem Deus - composta por Inácio, $O$ enfeitiçado e o incompleto Baltazar - a representação de um Rio de Janeiro tão decadente, corrupto e sombrio quanto vemos em Dentro da noite. No entanto, a proximidade mais peculiar de Lúcio Cardoso com o autor carioca se dá por um conto secundário de sua produção, publicado em 1946 no suplemento literário do jornal A manhã e republicado no mesmo espaço quatro anos mais tarde com algumas alterações ${ }^{10}$.

"A papoula azul", posteriormente nomeado "Simples encontro", apresenta em uma breve narrativa o caso de uma menina que, durante um piquenique na praia, é atraída por um homem misterioso que contrastava com a paisagem idílica em que se encontravam:

Era magro, alto e, menos do que sua estranha atitude de observação, o que nele me chamou a atenção desde o início foi o chocante contraste que oferecia com a paisagem: não havia nada em sua pessoa que lembrasse a claridade e a alegria que nos cercava, ao contrário, vestia-se severamente de preto e escondia mais ou menos o rosto à sombra de um chapéu também preto (CARDOSO, 1946, p.7)

Tal figura, além do contraste sombrio, se destacará por alguns paralelos que o aproximam dos vampiros vitorianos, como sua capacidade hipnótica - "Pouco a pouco senti que ele exercia certa atração sobre mim e, quase sem querer, e sem saber porque o fazia, fui me aproximando aos poucos" (p.7) - e sua palidez incomum - "Ao mesmo tempo que eu falava, pensava comigo mesmo: 'É um doente, só pode ser um doente. Nunca vi ninguém tão pálido assim..." (p.7).

10 E, cuja descoberta, eu devo ao prof. Julio França, que primeiro notou o paralelo entre ambos. 
É, no entanto, o desfecho do conto que mais chama a atenção. A misteriosa figura, através dessa atração inexplicável, conduz a menina para longe de seus amigos sobre o pretexto de ver uma papoula. Mesmo sabendo que papoulas não crescem ali, ela deixase levar até $\mathrm{o}$ alto de alguns rochedos marinhos, onde a ataca:

Ele se aproximou, como para mostrar-me a flor:

- Ali, bem ali.

Olhei de novo - e desta vez, senti de repente uma dor aguda, horrível, atravessar-me o braço. Dei um grito, sem compreender o que fosse, e erguendo-o, vi que o homem tinha enterrado nele um comprido e negro espinho de cactos (CARDOSO, 1946, p.7)

Dada a proximidade de temáticas e estilos dos autores e o inegável paralelo entre o modus operandi do psicopata de "Dentro da noite" e do misterioso homem de "A papoula azul" - além de um mesmo perfil de vítima -, podemos supor que o conto de Lúcio Cardoso fizesse, 25 anos após a morte de João do Rio, uma homenagem velada ao autor carioca, criando uma pequena reaparição de Rodolfo.

É, no entanto, Inácio, personagem central nos três romances da trilogia "O mundo sem Deus", que nos oferecerá um retrato mais completo do predador urbano cardosiano. Ao longo dos três romances, devido à diferença de foco narrativo, temos acesso a três perspectivas distintas do monstro que será Inácio: o monstro enquanto ameaça externa; o monstro enquanto besta interna; e as cicatrizes deixadas pelo monstro.

Em Inácio, vemos o personagem através da ótica de seu filho, Rogério, enquanto vamos sendo apresentados ao passado 
de Inácio, mediado pelo discurso de um homem que quer matálo, Lucas Trindade. Nesse romance, as caracterizações do pai de Rogério oscilam entre a repulsa, carregada de ódio pelo passado, e uma atração irresistivel, que faz com que Rogério, mesmo alertado sobre os pecados de seu pai, queira aproximar-se dele novamente. Inicialmente influenciado pelo ódio e medo de Lucas Trindade, que Rogério descobre ser antigo amante de sua mãe, Inácio é descrito como um ente quase sobrenatural:

- Vamos - disse Lucas -, pois tenho medo de não me controlar. Nem sabe você de que poderes é dotado esse demônio!

- Não acredito nos seus poderes - respondi eu, mais para atiça-lo do que mesmo por dar crédito às minhas palavras.

- Não? Pois há vários anos que não me abandona, que me persegue dia e noite, sem descanso. Até em sonhos me aparece. E como zomba de mim, como se ri, como bebe e vive satisfeito, esse monstro! $\mathrm{E}$ sempre o vi assim, com essa fisionomia que jamais envelhece, com o mesmo olhar e a mesma cara de boneca! (CARDOSO, 2002, p.86-87)

A descrição de Lucas, logo depois, é confirmada por Rogério que encontra na fisionomia do pai a mesma impressão perturbadora atestada pelo antigo inimigo de Inácio:

vi seu rosto pálido como se fosse de cera, corado ao centro, um rosto realmente de boneca, mas iluminado por tal expressão de ódio como jamais vi numa fisionomia humana. Não, ali falava alto alguma coisa mais extraordinária que a simples força que agitava o coração humilhado de Lucas... Aliás, devo declarar que a proximidade daquele homem causou-me uma espécie de estupor: não 
podia me mover, olhos cravados no seu rosto, no seu rosto horrendo, que eu tanto vira transitar nos meus pesadelos de criança (p.88)

Vemos nas descrições de Lucas e Rogério como, novamente, esse predador urbano cardosiano apresenta traços da caracterização dos vampiros em sua formação. Inácio apresenta uma fisionomia que jamais envelhece, um rosto pálido "como se fosse de cera" e seu olhar é capaz de causar "uma espécie de estupor".

Aproximando-se de Rogério a fim de descobrir o paradeiro de Lucas Trindade, Inácio mostrará também seu lado sedutor, dividindo a opinião do filho sobre ele:

Não sabia dizer se aquele homem me atraía ou causava repulsa. O certo é que suas possibilidades causavam-me uma singular fascinação (...). Devo declarar também que, nele, uma das qualidades que mais me impressionavam era a sua capacidade de transfiguração; ainda que se tratasse do fato de tomar uma laranjada, para Inácio esse episódio banal se convertia em algo de estranho e maravilhoso (p.110)

Ao fim da obra, após Lucas ter sido assassinado por Inácio com a ajuda do filho, Rogério perde a utilidade que tinha e, assim, Inácio parece deixar de esforçar-se para agradar o filho. Livre da influência magnética do pai e ainda traumatizado pela cena do assassinato, Rogério percebe pouco a pouco o monstro que era seu pai e, atormentado por aquele vislumbre, enlouquece. Descobrimos, assim, que o garoto narra a história de um sanatório no qual se encontrava internado após os eventos apresentados no romance. 
O segundo livro da trilogia inverte drasticamente essas perspectivas. Em $O$ enfeitiçado, quem narra é um Inácio mais velho, já esgotado pelos anos, arrependido de seu passado e buscando no reencontro com o filho perdido uma forma de redenção. $\mathrm{Na}$ perspectiva do próprio monstro, como no caso de "Dentro da noite", vemos ganhar destaque não o medo de tornar-se vítima, mas o medo dessa besta interior que pode eclodir de qualquer homem, o medo de que nos tornemos, de uma hora para outra, um monstro.

Nessa obra, intensificam-se algumas das características que aproximam Inácio do monstro vampiresco. Se em Inácio o ambiente já era carregado de sombras, vemos na segunda obra um protagonista plenamente notívago:

E era tarde, era quase noite, ou melhor, era precisamente essa hora que eu tanto amo, hora em que as ruas escurecem e a [sic] luzes se acendem. Nunca pude ficar em casa nesse momento. É preciso amar as cidades para adivinhar as horas em que palpita seu segredo mais fundo. É preciso ter os olhos bem abertos, os ouvidos à escuta, para perceber quando o mar se cala e a noite chega, com suas promessas e possibilidades. Ninguém saberá jamais o que é a noite para os noctívagos: eles se roçam nela, embriagam-se com sua cálida essência, resplandecem aos seus fogos concentrados. Desmesuradas, àquela hora as casas abrigavam a sombra (CARDOSO, 2002, p.156)

Dir-se-ia que uma ausência enorme se fizera no mundo, que uma única noite, vasta e repleta de silêncio, cobrira para sempre os meus passos (p. 200)

Visitando Lina, uma cartomante, a fim de tentar obter informações através de sua rede de contatos, esta vê em Inácio alguém que buscava 
"algo fundamental, como que o próprio alento da sua vida..." (p.169). Posteriormente Lina especifica mais, dizendo que "Ihe falta um elemento vital, um calor para este sangue que lhe corre nas veias" (p.207), e chega a conclusão: “O senhor não está vivo” (p.207).

Esse alento de vida será roubado de Adélia Val-Flor, suposta filha da cartomante, que lhe é apresentada como parte de um plano da mãe para extorquir-lhe o dinheiro. Inácio passa a levar Adélia para passear, ainda que a filha da cartomante seja, nas suas palavras, "uma criança, uma criança no sentido exato da palavra, tímida e mal vestida" (p.174). Conforme Inácio convivia com Adélia, projetava nela uma maturidade que claramente lhe faltava e, ao mesmo tempo, sentia-se mais vivo e afastado de seus tormentos. Esse processo, contudo, culmina naquilo que Lina esperava: Inácio, sentindo a necessidade de possuir Adélia, resolve comprá-la definitivamente. Pouco depois, começava a surgir em sua mente a consciência do desejo que se formava nele e, assim, a besta interior que voltava, depois de tantos anos, a atacar-lhe:

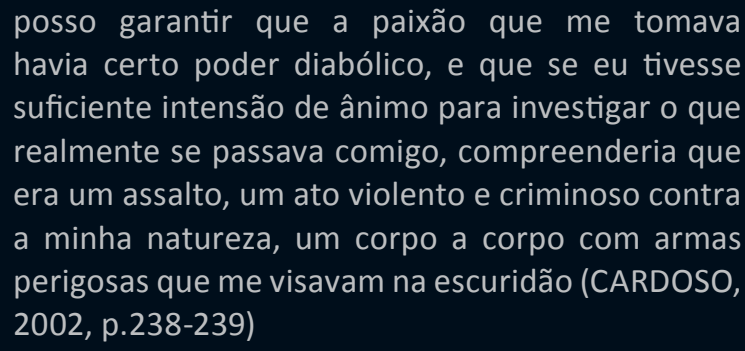

Inácio, tomado pelos impulsos, resolve embebedar a menina e levála para sua casa. Enquanto está desmaiada pelo álcool a ataca. Aqui, o que na literatura vampiresca é metáfora sexual, descarta a necessidade de símbolos e expõe um verdadeiro estupro à menina desacordada: 
Tive a impressão de que outra força me conduzia e me fazia agir, independente da minha vontade. Inclinei-me sobre Adélia adormecida e, tomando-a nos braços, colei à sua boca meus lábios ávidos. Aquele beijo não tinha gosto de coisa alguma, mas eu sentia palpitar junto à minha carne aquela vida cheia de calor e de intensidade, o que me dava momentaneamente uma sensação idêntica à da embriaguez. E confesso que não tive nenhum pudor, nenhum remorso em profanar aquele corpo de criança (p.249)

Baltazar não chegou a ser terminado por Lúcio Cardoso, mas, através dos trechos que já haviam sido produzidos pelo autor, é possível ver que o foco da narrativa seria justamente na vítima de Inácio, Adélia. Já mais velha, Adélia nunca consegue deixar para trás as marcas do ato a que foi submetida e vive uma vida marcada pelo trauma. Inácio, que morre no final de $O$ enfeitiçado após ser obrigado a se enforcar por um capanga de Lina como punição por não pagar a dívida contraída com ela, reaparece em Baltazar como um espectro na memória e nos pesadelos da menina:

Foi nesse instante, que senti a sua presença: talvez seja melhor dizer que senti a mesma impressão de antigamente, quando me diziam que "ele" estava na sala - e através da cortina, eu espiava o seu vulto detestado (p.297)

Não sei que esquisita emoção se apoderava de mim, mas era uma espécie de vertigem, um esmaecimento de todos os meus nervos, como se eu tivesse ingerido um narcótico. Sem dúvida era a presença daquele homem, tão forte, tão absoluta nas suas vagas de terror e de exaltação, o que produzia aquele sentimento de cansaço ou de embriaguez (p.299-300) 
Encerra-se assim a representação desse monstro urbano tanto em sua potencialidade, em Inácio, em sua concretização em 0 enfeitiçado e em suas reminiscências nos trechos de Baltazar. Se, em "Dentro da noite", a agulha servirá como proximidade com o ato vampiresco, Inácio abunda em índices que o aproximam de Drácula, velho aristocrata perdido em um Rio de Janeiro com ares de Londres gótica. Tal semelhança pode ainda ser reforçada se levarmos em conta que Lúcio Cardoso foi tradutor da obra de Stoker, tornando inegável sua relação com o romance vitoriano.

Pode-se ainda, para completar um percurso pelos predadores urbanos como figuras vampirescas na literatura brasileira, abordar uma obra mais recente: $O$ vampiro de Curitiba, de Dalton Trevisan. Seu título, assim como certo discurso difundido ao longo da obra, condensa justamente nossa hipótese sobre o conteúdo dos medos, ansiedades e desejos relacionados ao vampiro vitoriano.

Coletânea de contos, fragmentos da vida de Nelsinho, "O vampiro de Curitiba" usa o monstro vitoriano justamente como metáfora para um desejo incontrolável que tortura o personagem: o sexual. Em um longo fluxo de pensamento, o primeiro conto serve mais como manifesto da mente pervertida, como confissão que nos ajudará a ler seus atos nas histórias que se seguirão. Em tom delirante, expõe de forma truncada o misto de ódio e paixão que parece sentir por toda e cada mulher da rua, especialmente pelas mais novas, pelas virgens. Encara sua mera presença como provação e, diante daquilo que parecem despertar em seu interior, afirma:

Se não quer, por que exibe as graças em vez de esconder? Hei de chupar a carótida de uma por uma. Até lá enxugo os meus conhaques. Por causa 
de uma cadelinha como essa que aí vai rebolandose inteira. Quieto no meu canto, ela que começou. Ninguém dia que sou taradinho. No fundo de cada filho de família dorme um vampiro - não sinta gosto de sangue (TREVISAN, 1998, p.10)

O vampiro serve, assim, como símbolo para essa besta sexual que na visão de mundo de Nelsinho, habitaria no interior dos homens de forma geral. Se em cada filho de família habita um vampiro, Nelsinho completa sua teoria afirmando sobre as meninas que "[t]oda família tem uma virgem abrasada no quarto" (p.13).

No entanto, como veremos ao longo do livro, essa máxima representa apenas metade do universo feminino da obra. Para Nelsinho, as mulheres se dividem necessariamente entre o arquétipo da virgem - inocente, recatada, provocante - e o arquétipo da viúva, tão vampira quanto os rapazes, caçadora insaciável:

Não olhe, infeliz! Não olhe que você está perdido. É das tais que se divertem a seduzir o adolescente. Toda de preto, meia preta, upa lá lá. Órfã ou viúva? Marido enterrado, o véu esconde as espinhas que, noite para o dia, irrompem no rosto - o sarampo da viuvez em flor. Furiosa, recolhe o leiteiro e o padeiro. Muita noite revolve-se na cama de casal, abana-se com leque recendendo a valeriana. Outra, com a roupa da cozinheira, à caça de soldado pela rua (p.11)

De fato, se olharmos para a dinâmica de predador e presa ao longo das obras, a coletânea poderia muito bem se chamar Vampiros de Curitiba, uma vez que esse segundo tipo de mulher, experimentadas, donas de sua própria sexualidade, atacarão ao jovem e inexperiente Nelsinho tanto quanto ele o fará com as virgens que consegue conquistar. 
Nelsinho, de certa forma, incorpora um pouco de cada um de seus antecessores. Em sua loucura pelas virgens, protagonizará atos de violência sexual como aquele que marca Inácio e, atormentado por seus impulsos sexuais incontroláveis, se aproximará da psicopatia de Rodolfo. Por mais que o rapaz não encontre o refinamento sádico do personagem de João do Rio, parece haver, ao menos em seu discurso, grandes semelhanças entre os impulsos de ambos: "Ó bracinho nu e rechonchudo - se não quer por que mostra em vez de esconder? -, com uma agulha desenho tatuagem obscena" (TREVISAN, 1998, p.12).

A obra oscila entre episódios humorísticos, eróticos e mais sérios. Em dois deles, podemos ver com mais claridade o lado predatório de Nelsinho se desenvolvendo de forma mais ameaçadora. Em "Incidente na loja", tenta seduzir uma jovem vendedora, mas não resistindo ao impulso sexual que the vem e aproveitando que a loja estava vazia, leva-a ao fundo e estupra a menina, ainda que, de seu ponto de vista, tente convencer-se que ela queria e que, na verdade, ele seria a vítima: Óculo embaçado da moça, estava de olho aberto? Ela não se mexia, ofegante de medo ou prazer. Nelsinho enterravaIhe o nariz nos longos cabelos vermelhos - ai, Senhor, de nós dois qual é a vítima? (p.21)

No segundo episódio, muito mais violento, a presa é uma menina negra de dezesseis anos, vítima de um estupro coletivo do qual Nelsinho é um dos culpados. "Debaixo da ponte preta" é narrado na forma de sucessivas versões do caso, dadas na forma de depoimentos para o delegado que então investigava o caso. Vemos nesse conto novamente a tentativa de amenizar a culpa dos criminosos alegando - em algumas das versões - que a menina 
namorava um dos rapazes ou era uma prostituta ou ainda que o tinha feito por vontade própria. No entanto, através da repetição constante do mesmo horrendo ato, o conto transmite de forma incisiva o medo sentido por essas vítimas dos homens-vampiros que povoam a urbe, criaturas que, parecendo homens civilizados - casados, trabalhadores, servidores da justiça ou simples meninos - não precisam mais do que uma pequena oportunidade para transformarem-se em monstros:

Miguel de Tal, quarenta anos, casado, foguista, largou o serviço às dez e meia. Ao cruzar a linha do trem, avistou três soldados e uma dona em atitude suspeita. Sentiu um tremendo desejo de praticar 0 ato. Aproximou-se do grupo e, auxiliado pelos soldados, agarrou a desconhecida, retirando-Ihe a roupa e com ela mantendo relação, embora à força. Derrubou-a e, para abafar os gritos, tapou-Ihe o rosto com o casaco de foguista. Saciado, ajudou os soldados que, cada um por sua vez, usaram a moça, observados à distância por alguns curiosos, até que dois deles também se serviram da negrinha (TREVISAN, 1998, p.77)

Ainda que a literatura brasileira ofereça inúmeros casos de assassinos, psicopatas e estupradores, muitos dos quais conseguiriam ser mais próximos à brutalidade dos atos de Jack, optamos por selecionar esses três a fim de ilustrar não apenas como os temores encontrados na literatura vampiresca vitoriana se perpetuaram ao longo do tempo através da literatura centrada em predadores urbanos, como também para mostrar como mesmo que o vampiro enquanto forma não seja utilizado com frequência em nossa literatura, sua apropriação enquanto metáfora, enquanto signo que aponta para esse monstro vitoriano, se dá não apenas na 
virada do século, mas continua até hoje servindo como associação aos medos que anteriormente já expressava.

Se o Brasil não pode ser visto como um país em que vingaram muitas narrativas sobre vampiros, não nos faltaram alternativas para manifestar o conteúdo dos medose anseios culturais inspirados por essas criaturas: atendendo à demanda pelo documental, essas narrativas mostram que o dom proteico do vampiro pode ir além de suas metamorfoses usuais, permitindo que mesmo fora do campo sobrenatural, seus horrores se manifestem através de um monstro assustadoramente humano.

\section{REFERÊNCIAS}

BLOOM, Clive (2017). "Dracula and the Psychic World of the East End of London". In: CRIŞAN, Marius-Mircea. Dracula: an international perspective. Londres: Palgrave MacMillan, p.119-137.

CARDOSO, Lúcio (1946). "A papoula azul”. A manhã, Suplemento Letras e artes, 25.Ago, 7.

(2002). Inácio, O enfeitiçado e Baltazar. Rio de Janeiro: Civilização Brasileira.

CAWELTI, John (1975). "The New Mythology of Crime". Boundary 2, 3(2), 324-357. COHEN, Jerome Jefrrey (2000). "A cultura dos monstros: sete teses". In: SILVA, Tomaz Tadeu da (Org.). Pedagogia dos monstros: os prazeres e os perigos da confusão de fronteiras. Belo Horizonte: Autêntica. p.23-60.

COLAVITO, Jason (2008). Knowing Fear: Science, Knowledge and the Development of the Horror Genre. Jefferson, NC: McFarland.

FRANÇA, Julio (Org.) (2017). Poéticas do mal: a literatura do medo no Brasil (1840-1920). Rio de Janeiro: Bonecker.

RIO, João do (2002). Dentro da noite. São Paulo: Antiqua.

SADE, Marquês de (1979). Justine: ou as desgraças da virtude. Edmond Jorge (Trad.). Rio de Janeiro: Entrelivros cultural. 
SIMPSON, Philip (2010). "Noir and the Psycho Thriller". In: HORSLEY, Lee; RZEKPA, Charles (Org.). A companion to Crime Fiction. Chichester: Wiley-Blackwell. TREVISAN, Dalton (1998). O vampiro de Curitiba. Rio de Janeiro: Record. 